\title{
Lusioersily
}

\section{Ultrasmall radio frequency driven microhollow cathode discharge}

Mahony, CMO., Gans, T., Graham, WG., Maguire, PD., \& Petrović, Z. (2008). Ultrasmall radio frequency driven microhollow cathode discharge. Applied Physics Letters, 93(1), 011501. https://doi.org/10.1063/1.2956412

Link to publication record in Ulster University Research Portal

\section{Published in:}

Applied Physics Letters

Publication Status:

Published (in print/issue): 01/07/2008

DOI:

10.1063/1.2956412

\section{Document Version}

Author Accepted version

\section{General rights}

Copyright for the publications made accessible via Ulster University's Research Portal is retained by the author(s) and / or other copyright owners and it is a condition of accessing these publications that users recognise and abide by the legal requirements associated with these rights.

\section{Take down policy}

The Research Portal is Ulster University's institutional repository that provides access to Ulster's research outputs. Every effort has been made to ensure that content in the Research Portal does not infringe any person's rights, or applicable UK laws. If you discover content in the Research Portal that you believe breaches copyright or violates any law, please contact pure-support@ulster.ac.uk. 


\title{
Ultrasmall radio frequency driven microhollow cathode discharge
}

\author{
C. M. O. Mahony, ${ }^{1, a)}$ T. Gans, ${ }^{2}$ W. G. Graham, ${ }^{2}$ P. D. Maguire, ${ }^{1}$ and Z. Lj. Petrović ${ }^{3}$ \\ ${ }^{1}$ NIBEC, University of Ulster, BT37 OQB Northern Ireland, United Kingdom \\ ${ }^{2}$ Centre for Plasma Physics, Queen's University Belfast, BT7 1NN Northern Ireland, United Kingdom \\ ${ }^{3}$ Institute of Physics, P.O. Box 68, 11080 Zemun, Serbia
}

(Received 4 April 2008; accepted 17 June 2008; published online 8 July 2008)

\begin{abstract}
We have operated 25-100 $\mu \mathrm{m}$ diameter radio frequency microhollow cathode discharges stably, for many hours, in neon and in argon. Electrical and spectroscopic measurements were used to explore three possible electron heating modes and obtain detail regarding the electron energy distribution. Analysis points to the possibility of pendular electron heating at low voltages. () 2008 American Institute of Physics. [DOI: 10.1063/1.2956412]
\end{abstract}

There has been considerable interest in reducing hollow cathode dimensions to below $100 \mu \mathrm{m}$ for high plasma density and/or high (atmospheric) pressure operation. ${ }^{1,2}$ These microhollow cathodes (MHCs) are operated under dc or pulsed-dc conditions and have an open cylinder ${ }^{3}$ or well structure. ${ }^{4,5}$ The mechanisms at play in MHCs are as yet unclear. Kim et al. ${ }^{1}$ suggest that true hollow cathode operation, involving pendular electron motion, is possible up to $100 \mu \mathrm{m}$ diameter at 10 Torr. Models by Kushner ${ }^{2}$ show that ionization occurs predominantly within the sheath, due to extremely short mean free paths compared to discharge dimensions, and has estimated an upper limit of around $20 \mu \mathrm{m}$ diameter for pendular motion at 500 Torr. Further scaling of dc-based devices is limited by reliability issues due to high gas temperatures and cathode sputtering. With high frequency (rf) operation, electron heating during the sheath expansion phase may offer an alternative or complementary plasma sustaining mechanism to secondary electron emission $(\gamma$-mode $)$ at the cathode. In a conventional parallel-plate rf plasma, such sheath expansion heating is less important at high pressures. However for the rf-MHC, the plasma is almost totally surrounded by the oscillating cathode sheath and dominant ionization may therefore occur via such heating. This has beneficial implications for reliability at these dimensions since the $\gamma$-mode self-sustaining requirement would be reduced. This further implies that in the rf-MHC, pendular effects may trap electrons as they gain energy via multiple electron-sheath reflections. Our aim is to obtain stable rf-MHC operation in order to explore the dominant fundamental mechanisms at reduced scales. Here we report MHC structures operating under rf excitation, with diameters $(D)$ ranging from 25 to $100 \mu \mathrm{m}$. We present initial electrical measurements for a $50 \mu \mathrm{m}$ diameter rf-MHC neon discharge (MHCD) and obtain effective electron temperature estimates via optical emission spectroscopy (OES) of a neon-argon rf-MHCD.

The MHCD, Fig. 1, consists of stainless steel apertured cathode and movable aluminum anode. While not strictly correct, for convenience we use the term "cathode" to describe the apertured if driven electrode and "anode" for the electrode earthed through $R_{m}$. In a conventional MHC, there is often a dielectric spacer between anode and cathode; here a variable gap $(G)$ provides greater experimental flexibility. The MHC is mounted in a vacuum chamber with

${ }^{a)}$ Electronic mail: c.mahony@ulster.ac.uk. controlled gas mixture and pressure ( $p=1-600$ Torr). rf power is applied to the cathode through a matching network; the anode is earthed via the anode current $\left(I_{a}\right)$ measurement resistor $R_{m}$. Cathode voltage $\left(V_{c}\right)$ was measured with a high voltage probe attached to a voltage divider. Measurement points connect to the source through the vacuum wall by $50 \Omega$ coaxial line (length $\approx \lambda / 4$ of fifth harmonic). Spectra were captured via fiber optics at A and B in Fig. 1 by a $0.25 \mathrm{~nm}$ resolution spectrometer.

A number of discharge modes occur, depending on power and pressure conditions. The red parallel-plate discharge (PPD) between anode and cathode (region X) is seen through the $50 \mu \mathrm{m}$ aperture in Fig. 2(a) and a bright MHCD is visible within the aperture (region Y) in Fig. 2(b). The PPD typically turns on at 1-3 W, depending on pressure, while the MHCD turns on at $7-20 \mathrm{~W}$ but is sustainable down to $3-7 \mathrm{~W}$. The PPD is always on when the MHCD is on, but at low power the PPD can occur without a MHCD [Fig. 2(a)].

The rf measurement system, Fig. 1, was calibrated for dc and first harmonic magnitudes. Remote measurement mainly affects phase, especially at higher harmonics. The MHCD turn-on behavior in the range 100-500 Torr is shown in Fig. 3 . Note that the PPD was on throughout. Here, $V_{c r f}$, the measured cathode peak-to-peak voltage amplitude at turn-on (observed visually), falls with increasing $p G$. It is not known if $p D$ or $p G$ scaling, if any, dominates in these devices. If the MHCD follows $p G$ scaling, the data are below the Paschen minimum estimated, from Fig. 3, as $>10$ Torr $\mathrm{cm}$. This minimum is much higher than the 1 Torr $\mathrm{cm}$ value measured (in argon) for the same device without aperture for rf (Fig. 3) and dc operation. Published dc data ${ }^{6}$ for $\mathrm{Ne}$ and $\mathrm{Ar}$ show minima at $p d \approx 4$ and 2 Torr $\mathrm{cm}$, respectively. The maximum MHCD power density is $\sim 100 \mathrm{~kW} \mathrm{~cm}^{-3}$. Reliable operation was obtained with these devices in MHC mode for $>3 \mathrm{~h}$ total test time and detailed lifetime studies are underway.

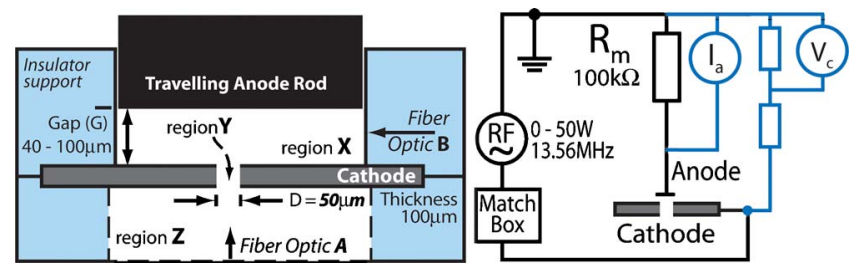

FIG. 1. (Color online) MHC structure and circuit diagram. Regions X, Y, and $\mathrm{Z}$ and fiber optics $\mathrm{A}$ and $\mathrm{B}$ are referred to in the text. 

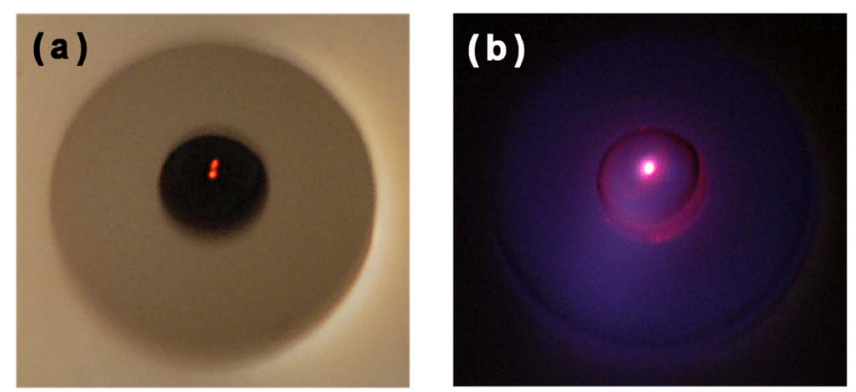

FIG. 2. (Color online) (a) Ne 500 Torr, $6 \mathrm{~W}$ : PPD in region X, seen through the $50 \mu \mathrm{m}$ aperture (the off-center image is a reflection in the vacuum window) and (b) Ne, 250 Torr, $11 \mathrm{~W}$ : bright rf MHCD in region Y.

MHCD $I-V$ measurements (PPD on) were obtained at $\mathrm{rf}$ powers from 5 to $20 \mathrm{~W}$ for various pressures and gaps. The observed increase in conductivity, Fig. 4(a), is consistent with the expected increase in plasma density with power. At $V_{c \mathrm{rf}}>400 \mathrm{~V}$, the conductive plasma allows a small but distinct positive dc to flow to the anode, through the MHCD, from surrounding earthed components, leading to an effective increase in anode/cathode area ratio and a marked increase in the cathode dc self-bias. The $I_{a}$ waveform is almost sinusoidal when only the PPD is on but becomes increasingly triangular for the MHCD as power is increased. Figure 4(b) shows elevated $I_{a r f}$ harmonic content as $V_{c r f}$ increases above $\sim 400 \mathrm{~V}$; note that MHCD and PPD are on for all data. Since the additional harmonic content is only seen in MHCD, this could be due to periodic current peaks, consistent with a MHC sustaining mechanism based on expanding sheath heating. Detailed phase measurements are underway to confirm this hypothesis.

All spectral lines observed in the discharges lie between 580 and $710 \mathrm{~nm}$ and were identified as neon, Fig. 5. Spectrum (a) shows the low rf power case (PPD only). The MHCD was turned on and then power reduced to $5.5 \mathrm{~W}$. The PPD spectra (not shown) increased by $\sim 30$ times with near identical line ratios, indicating an increase in plasma density once the MHCD is on but with little change in electron energy probability function (EEPF). At high powers, the PPD spectrum (b) displays lines with both decreased (e.g., $585.2 \mathrm{~nm}$ ) and increased (e.g., 640.0 and $703.0 \mathrm{~nm}$ ) intensities compared to (a). For high power MHCD, Fig. 5(c), taken simultaneously with (b) we also note more marked intensity

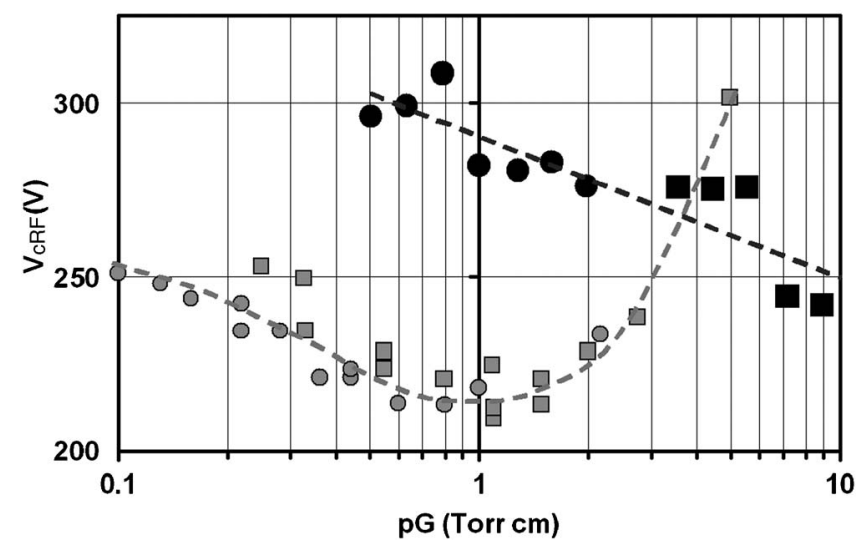

FIG. 3. $V_{c \mathrm{rf}}$ at turn-on vs $p G, G=40 \mu \mathrm{m}$ (circles) and $G=200 \mu \mathrm{m}$ (squares). Black: Ne MHCD $D=50 \mu \mathrm{m}$; gray: Ar PPD no aperture. Dashed lines are an aid to the eye. optic A), 330 Torr, $17.5 \mathrm{~W}$.
Author complimentary copy. Redistribution subject to AIP license or copyright, see http://apl.aip.org/apl/copyright.jsp
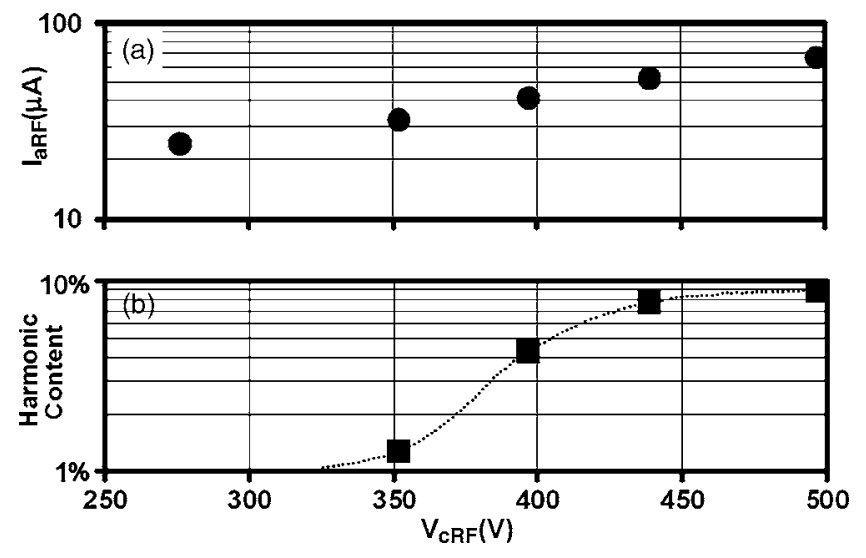

FIG. 4. MHCD $I_{\text {arf }}$ vs $V_{c \mathrm{rf}}$ : (a) fundamental and (b) $I_{a} \mathrm{HC}(n \leqslant 5$ harmonic content normalized to fundamental) 500 Torr Ne $G=40 \mu \mathrm{m} D=50 \mu \mathrm{m}$.

changes for the same lines as (b) as well as for other lines. This indicates a difference between EEPFs in PPD and MHCD regions. It also suggests that the change in PPD line intensity at higher powers (b) is due to the influence of the MHCD. However, there are a number of features in (b) not found in (a) or (c), thus implying additional mechanisms.

OES was used to investigate high energy electron populations for neon-argon MHCDs and PPDs with gas ratio $\mathrm{Ne}: \mathrm{Ar}=98: 2$ at pressures from 300 to 500 Torr. EEPF details were obtained by comparing calculated values [Eq. (1)] with measured integrated intensity ratios of neon $(585.2 \mathrm{~nm}$, $19 \mathrm{eV})$ and argon $(750.4 \mathrm{~nm}, 13.5 \mathrm{eV}) 2 p_{1}$ emission lines

$$
\frac{I_{\mathrm{Ne} 2 p 1}}{I_{\mathrm{Ar} 2 p 1}}=\frac{n_{\mathrm{Ne}}}{n_{\mathrm{Ar}}} \frac{A_{i \mathrm{Ar}}}{A_{i \mathrm{Ne}}} \frac{\lambda_{\mathrm{Ar}}}{\lambda_{\mathrm{Ne}}} \frac{S_{\mathrm{Ne}}}{S_{\mathrm{Ar}}} \frac{A_{i k \mathrm{Ne}}}{A_{i k \mathrm{Ar}}} \frac{E_{\mathrm{Ne}}}{E_{\mathrm{Ar}}} .
$$

Sensitivities $(S)$ were determined from instrumental and optical path considerations. Excitation rates $\left(E_{\mathrm{Ne}}, E_{\mathrm{Ar}}\right)$ were evaluated, as a function of average electron energy $\left(E_{\mathrm{av}}\right)$ for Maxwellian- or Druyvesteyn-like EEPFs, using known excitation cross sections ${ }^{7,8}$ and neutral densities. $E_{\text {av }}$ was determined by minimizing the difference between calculated and measured line ratios. For Maxwellians $k T_{e}=\frac{2}{3} E_{\mathrm{av}}$, for nonMaxwellians we similarly define an "effective electron temperature" $k\left\langle T_{e}\right\rangle=\frac{2}{3} E_{\mathrm{av}}$. The analysis gives $T_{e}$ and $\left\langle T_{e}\right\rangle$ for Maxwellian- and Druyvesteyn-like distributions, respectively. It also gives $T_{H}\left(\approx T_{e}\right)$ often referred to as the local temperature at high energy $\left(E_{H}\right)$; for our measurements $13.5<E_{H}<19 \mathrm{eV}$. The EEPF over $E_{H}$ is particularly relevant because these electrons dominate ionization/excitation processes. De-excitation rates $A_{i}$ were calculated using known Einstein coefficients $A_{i k}$ (Ref. 9) and deactivation (quenching) estimates. No published collisional quenching coefficients for neon $\left(k_{\mathrm{Ne} 2 p 1: \mathrm{Ne}}\right.$ and $\left.k_{\mathrm{Ne} 2 p 1: \mathrm{Ar}}\right)$ exist and so are

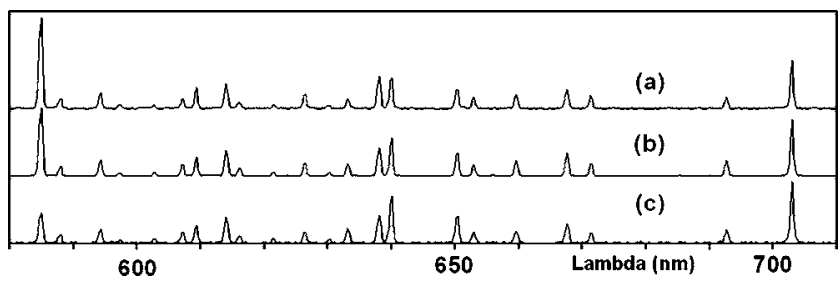

FIG. 5. Ne spectra, normalized to least sensitive lines, offset for clarity. (a) PPD region X, fiber optic B, MHD off, 250 Torr, $3.5 \mathrm{~W}$ : simultaneous spectra; (b) PPD (region X, fiber optic B); and (c) MHCD (region Y, fiber 

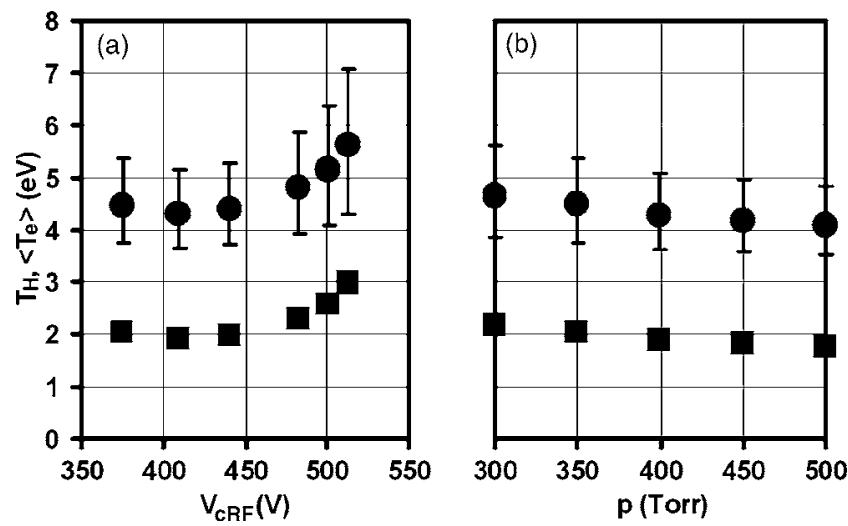

FIG. 6. MHCD characteristics. $T_{H}$ and $\left\langle T_{e}\right\rangle$ vs (a) $V_{c \mathrm{rf}}$ at 400 Torr and (b) pressure at $11 \mathrm{~W} . D=50 \mu \mathrm{m}, G=40 \mu \mathrm{m}, \mathrm{Ne}: \mathrm{Ar}=98: 2$. Squares: Maxwellian solutions, circles: Druyvesteyn-like. Range bars on Druyvesteyn-like solutions indicate sensitivity to variation in the unknown neon quenching rates from 2 times to 20 times $k_{\mathrm{Ar} 2 p 1: \mathrm{Ar}}$.

estimated $^{10}$ as five times that for argon $\left(k_{\mathrm{Ar} 2 p 1: \mathrm{Ar}}\right)$ suggested by measurements based on the work of Gans et al. ${ }^{11}$ This OES methodology was compared with Langmuir probe EEPFs from a large-scale inductively coupled plasma source at low pressure (no quenching) and good agreement was obtained.

We consider the populations, Fig 6, to be nonMaxwellian because EEPFs based on the observed $T_{H}$ $\left(1.7 \mathrm{eV}<T_{H}<2.9 \mathrm{eV}\right)$ imply much fewer cold $(<1 \mathrm{eV})$ electrons than expected. The $\left\langle T_{e}\right\rangle$ increase above $450 \mathrm{~V}$, Fig. 6(a), follows similar increases in $V_{c \mathrm{dc}}$ and harmonic content (Fig. 5) at high voltages $(\sim 400 \mathrm{~V})$, suggesting markedly different MHCD characteristics. There are no relevant experimental publications over the pressure range 300-500 Torr; however, the observed reduction in $\left\langle T_{e}\right\rangle$, Fig. 6(b), and $T_{H}$ is consistent with pressure dependent depletion over $E_{H}$ presented in dc-HC/MHC models. ${ }^{1,12,13}$ Simultaneous PPD measurements (region $\mathrm{X}$ ) give $T_{H} \sim 20 \mathrm{eV}$, evidence of a fast electron tail typical of capacitively coupled plasmas; gas ratios in the small volume require consideration before this is confirmed.
In conventional rf plasmas, the presence of harmonics is indicative of sheath-related or Ohmic rather than $\gamma$-mode heating. On this basis we postulate that in our rf-MHC devices, at low voltage, the average MHC sheath width is relatively large compared to the diameter. Hence the intersheath distance may be short enough for electrons to interact with both sheaths. This could allow a pendular trapping and heating mode, due to multiple sheath reflections, which would then be superseded by conventional sheath-related heating as the sheath width reduces with higher plasma densities at higher voltages. It is worth pursuing kinetic modeling of $\mathrm{PPD} / \mathrm{MHCD}$ interactions and the effect of complex electron transport $^{14}$ on our considerations of electron energy distributions. It is also important to test the representation of surface secondary electron production because it will be necessary to extend these $\gamma$ mechanisms as dimensions reduce. ${ }^{15}$

${ }^{1}$ G. J. Kim, F. Iza, and J. K. Lee, J. Phys. D 39, 4386 (2006).

${ }^{2}$ M. J. Kushner, J. Phys. D 38, 1633 (2005).

${ }^{3}$ X. Aubert, G. Bauville, J. Guillon, B. Lacour, V. Puech, and A. Rousseau, Plasma Sources Sci. Technol. 16, 23 (2007).

${ }^{4}$ J. P. Boeuf, L. C. Pitchford, and K. H. Schoenbach, Appl. Phys. Lett. 86, 071501 (2005).

${ }^{5}$ J. G. Eden, S. J. Park, N. P. Ostrom, S. T. McCain, C. J. Wagner, B. A. Vojak, J. Chen, C. Liu, P. von Allmen, F. Zenhausern, D. J. Sadler, C. Jensen, D. L. Wilcox, and J. J. Ewing, J. Phys. D 36, 2869 (2003).

${ }^{6}$ M. A. Lieberman and A. J. Lichtenberg, Principles of Plasma Discharges and Materials Processing (Wiley, Hoboken, NJ, 2005), p. 547.

${ }^{7}$ J. E. Chilton, J. B. Boffard, R. S. Schappe, and C. C. Lin, Phys. Rev. A 57, 267 (1998).

${ }^{8}$ J. E. Chilton, M. D. Stewart, Jr., and C. C. Lin, Phys. Rev. A 61, 052708 (2000).

${ }^{9}$ Y. Ralchenko, A. E. Kramida, J. Reader, and NIST ASD Team, NIST Atomic Spectra Database, http://physics.nist.gov/asd3.

${ }^{10}$ A. Francis, T. Gans, K. Niemi, U. Czarnetzki, V. Schulz-von der Gathen, and H. F. Döbele, Proc. SPIE 4460, 122 (2002).

${ }^{11}$ T. Gans, C. C. Lin, V. Schulz-von der Gathen, and H. F. Döbele, Phys. Rev. A 67, 012707 (2003).

${ }^{12}$ G. M. Petrov and D. Zhechev, Phys. Plasmas 9, 1815 (2002).

${ }^{13}$ R. R. Arslanbekov, A. A. Kudryavtsev, and R. C. Tobin, Plasma Sources Sci. Technol. 7, 310 (1998).

${ }^{14} Z$. Lj. Petrović, M. Šuvakov, Ž. Nikitović, S. Dujko, O. Šašić J. Jovanović, G. Malović, and V. Stojanović, Plasma Sources Sci. Technol. 16, S1 (2007).

${ }^{15}$ M. Radmilović-Radjenović and B. Radjenović, Plasma Sources Sci. Technol. 16, 337 (2007). 